\title{
Consignas y carnaval en el movimiento estudiantil colombiano: una disputa por lo social
}

\author{
Margarita Rosa Vargas Torres*
}

\section{Resumen}

Este artículo está dividido en tres partes, en la primera, se hace una breve descripción del contexto en el que se ubica la discusión sobre una manifestación específica del movimiento estudiantil como son las consignas y su capacidad para expresar y producir subjetividad, así como su capacidad para visibilizar problemas educativos. En segundo lugar, se plantea que las consignas y las formas carnavalescas en las que el movimiento estudiantil las enuncia, producen y expresan subjetividad política entendida como la construcción de otros sentidos alternativos a los sentidos del orden hegemónico neoliberal y que estas consignas en últimas expresan sus demandas. La tercera parte se concentra en las prácticas carnavalescas del movimiento estudiantil y sus implicaciones.

Palabras clave: Consignas; movimiento estudiantil; carnaval; subjetividad política; universidad pública.

\section{Slogans and carnival in the colombian student movement: a dispute for the social}

\begin{abstract}
This article is divided in three parts. In the first one, a brief description is made of the context in which the discussion about a specific manifestation of the student movement takes place, such as slogans, and their capacity to express and produce subjectivity, as well as their capacity to make educational problems visible. In the second part, it is suggested that the slogans and the carnival-like forms in which the student movement enunciates them, produce and express political subjectivity, which is understood as the construction of other meanings alternative to those of the neoliberal hegemonic order. These slogans ultimately express claims of the students movement. The third part focuses on the carnival practices of the student movement and their implications.
\end{abstract}

Keywords: Slogans; student movement; carnival; political subjectivity; public university

* Profesora asociada de la Universidad Distrital Francisco José de Caldas, Colombia ‘mrvargast69@gmail.com».

Recibido: 14 de mayo de 2019 | Revisado: 12 de diciembre de 2019 | Aceptado: 15 de enero de 2020 Para citar este artículo: Vargas Torres, Margarita Rosa. "Consignas y carnaval en el movimiento estudiantil colombiano: una disputa por lo social”. Comentario Internacional, n. ${ }^{\circ} 19$ (2019): 165-188.

doi: $10.32719 / 26312549.2019 .19 .7$ 


\section{Introducción}

A

lgunas de las consignas que se agitaron durante el paro estudiantil del año 2011 enuncian Es mejor perder un semestre en la universidad que la universidad en un semestre, La universidad no se vende, se defiende; las universidades públicas no son empresas, más lápices, menos balas, ${ }_{i}$ Resistencia!! y la consigna del año 2017 propone Ser Pilo No Paga si la pública se acaba. Ellas reactivan reclamos que evidencian por un lado, la resistencia a las políticas neoliberales de privatización de la educación y por otro la defensa de lo que significa la Universidad y en particular la Universidad Pública en una sociedad. A través de la construcción de nuevos sentidos, de significantes que aglutinen es posible romper con los procesos de representación hegemónicos y esto se da mediante proyectos políticos que se juegan ideales en marcos identitarios.

En el artículo que se hace en el marco de mi tesis doctoral, ${ }^{1}$ se desarrolla la idea de que el movimiento estudiantil colombiano a través de sus consignas visibiliza y pone en la agenda del debate público unas demandas alrededor de la educación como derecho, el financiamiento de la educación a la oferta y no a la demanda donde la educación pública se ubica como estandarte de la sociedad.

La subjetividad política de los movimientos sociales que busco realzar en este artículo se opone, resiste y contrarresta la subjetividad instituida por el modelo neoliberal que está en crisis, lo cual abre posibilidades para otras formas alternativas de acción social ${ }^{2}$ entre las que se inscriben las prácticas sociales y comunicativas novedosas del movimiento estudiantil. Dichas prácticas alternativas de resistencia se dan en parte a través de las acciones colectivas en las que se expresan unas consignas y se producen unos espacios de enunciación carnavalescos que son solamente una manifestación de la producción simbólica de los movimientos sociales. ${ }^{3}$

1. La tesis doctoral se realiza en el Doctorado en Estudios Sociales de la Universidad Distrital Francisco José de Caldas de Bogotá, se titula El movimiento estudiantil universitario colombiano 2011-2018: Constitución de sujetos y subjetividades políticas y se hace en el marco del grupo de investigación Vivencias adscrito al mismo Doctorado.

2. Gustavo Xavier Ayala Cruz, "Izquierdas latinoamericanas: de la alternancia a la alternativa", Comentario Internacional, . $^{\circ} 7$ (2006): 79-92.

3. Otras dimensiones además de las consignas y lo carnavalesco en que los movimientos sociales producen y expresan subjetividad colectiva se podrían rastrear en sus documentos internos, en sus pronun- 
Esta discusión se ubica en una perspectiva epistemológica del lenguaje interpretativa, representacional y sociocultural. Las emergencias que visibilizan las consignas se relacionan con los repertorios de protesta así como con un lenguaje festivo, performativo y carnavalesco con el que los estudiantes posicionan unos discursos y producen y expresan una subjetividad política alternativa a la hegemónica privatizadora y neoliberal. Las formas carnavalescas corresponden a escenarios lúdicos en los que se hacen públicas las demandas a través de las consignas.

Las orientaciones teóricas que guían la investigación que da origen a las reflexiones de este artículo se ubican en dos abordajes: Uno, el de los movimientos sociales y dos, el de la sociología cultural. Las teorías de los movimientos sociales y de la acción colectiva aportan en la comprensión de los cambios y las permanencias que se han dado en las últimas décadas con respecto a las formas de hacer y entender la política y a las nuevas formas de acción social. Desde esta perspectiva se focaliza en lo identitario, la memoria, lo político y lo colectivo. ${ }^{4}$

Desde la sociología cultural es posible revisar las formas de sociabilidad cotidianas que se trasforman con las condiciones estructurales y las maneras como los sujetos establecen relaciones sociales en los diferentes ámbitos de la vida con variables como el territorio, el tiempo libre, la afectividad, las formas de participación colectiva, las representaciones sociales. En este abordaje se observa más allá de lo político que se expresa en la subjetividad/ subjetivación como categoría central que se manifiesta en formas de integración alternativa frente a la deslegitimación de lo instituido, tramas de sociabilidad, vida cotidiana, creencias, representaciones, imaginarios, utopías. ${ }^{5}$

La metodología en la que se enmarca el trabajo aquí presentado es de corte crítico-social, ya que la naturaleza del análisis de las posibilida-

ciamientos orales y escritos, en sus símbolos, grafitis, nombres que le dan a sus sedes, emisoras, formas de sociabilidad en sus espacios de encuentro, etc.

4. Joël Candau, Memoria e Identidad, trad. Eduardo Rinesi (Argentina: Ediciones del Sol, 2001), 9-202; Elizabeth Jelin, Los trabajos de la memoria (Madrid: Siglo XXI, 2002), 1-98; George Yudice, El recurso de la cultura: usos de la cultura en la era global (Barcelona: Gedisa, 2002), 23-55; Alberto Melucci, Acción colectiva, vida cotidiana y democracia (México: El Colegio de México, 1999), 25-54.

5. Jeffrey Alexander, "Pragmática cultural. Un nuevo modelo de performance social", Revista Colombiana de Sociología, n. ${ }^{\circ} 24$ (2005): 9-67; Lucía Corsiglia Mura, Jóvenes piqueteros y encapuchados: algunas preguntas sobre las marcas de lo plebeyo en las formas de la acción colectiva (Argentina: Ediciones de Periodismo y Comunicación Social / Observatorio de Jóvenes, Comunicación y Medios, 2012), 13-159; Cornelius Castoriadis, La institución imaginaria de la sociedad (Buenos Aires: Tusquets, 1999), 121-95. 
des políticas del movimiento estudiantil universitario colombiano implica comprender las relaciones entre la verdad, el poder y el pensamiento. De esta manera, se cuestiona el orden establecido, al tiempo que se plantea la apuesta de comprender y fortalecer procesos alternativos para la constitución de sujetos políticos. En ese sentido se plantean dos etapas, la primera se concibe como de orden descriptivo y la segunda de orden prospectivo y comprensivo. La etnografía crítica desde una perspectiva relacional, política y visual que involucra las relaciones entre los sujetos y de estos con el Estado permitirá dar cuenta de las prácticas o de los sentidos que los sujetos estudiantes universitarios le dan a la acción colectiva.

Lo crítico implica el reconocimiento de las asimetrías sociales, de las relaciones de poder sociales e históricamente constituidas; ${ }^{6}$ lo relacional porque se concibe un sujeto social, colectivo interactivo e intersubjetivo; lo político por su parte se refiere a las posibilidades que desde lo subalterno se configuran para disputar el orden social con el establecimiento y lo visual ${ }^{7}$ porque se abordarán piezas de la producción simbólica de los estudiantes como es el caso de las consignas y toda la condensación imaginaria que contienen desde una apuesta crítico descriptiva que usará como herramienta el análisis de contenido.

El paquete técnico con sus herramientas de investigación incluye un dispositivo conversacional que abarca entrevistas y grupos de discusión. A través de ellos se producen unos discursos narrativos que permiten abordar los significados y los sentidos que los sujetos en su interacción le atribuyen a la realidad social. Con los grupos de discusión en particular se observa el sentido social en el discurso que se produce a través de la interacción y la interpelación mutua. ${ }^{8}$ Veamos la aplicación de algunos de estos presupuestos teóricos y de esta metodología en un aspecto específico de la investigación: las consignas y las formas carnavalescas como disputa por lo social.

6. Joe Kincheloe y Peter Mclaren, "Replanteo de la teoría crítica y de la investigación cualitativa", en Manual de investigación cualitativa, comps. Norman K. Denzin e Yvonna S. Lincoln (Barcelona: Gedisa, 2012), 241-315.

7. Pablo Páramo, La investigación en Ciencias Sociales (Bogotá: Universidad Piloto de Colombia, 2013), 23-180.

8. Bernardo Russi, "Grupos de discusión: De la investigación social a la investigación reflexiva" en Técnicas de investigación en sociedad, cultura y comunicación, coord. Luis Jesús Galindo Cáceres (México D.F.: Addison Wesley Longman, 1998), 75-116; Francisco Sierra, "Función y sentido de la entrevista cualitativa en investigación social" en Técnicas de investigación en sociedad, cultura y comunicación, coord. Luis Jesús Galindo Cáceres (México D.F:: Addison Wesley Longman, 1998), 277-345. 


\section{La historicidad de lo social en el movimiento estudiantil del siglo XX}

La historicidad nos permite comprender un fenómeno al reconstruir aspectos de su pasado como memoria, de su presente como experiencia y de su futuro como proyecto. ${ }^{9}$ Es en este sentido que se localiza históricamente la manera como a través de sus repertorios de acción -consignas presentadas con formas carnavalescas- se enuncian unas demandas gremiales y políticas del movimiento estudiantil y se abren unas problematizaciones en el campo de la educación que ya han existido, pero que se reactualizan con la movilización y el flujo del movimiento estudiantil. Las problematizaciones que se discuten aquí se expresan en el marco empírico por la deuda histórica del Estado con la educación pública colombiana que para la fecha asciende a los 16 billones de pesos y en el endeudamiento de las familias de instituciones públicas y privadas que para poder acceder a la educación superior tienen que hacer préstamos ante el Instituto Colombiano de Crédito Educativo y Estudios Técnicos en el Exterior (ICETEX) o ante otras entidades bancarias.

A nivel internacional, está dada por la crisis de los metarelatos, que instaura otras lógicas en las formas de pensar y de actuar de los sujetos. En los años setenta, antes de la crisis de los metarelatos, periodo de auge del marxismo-leninismo-maoísmo, las consignas de los estudiantes y sus debates hablaban de una alianza de clases revolucionarias -obrero-campesina- para la toma del poder bajo la dirección del proletariado. Por ejemplo, se escuchaba El pueblo unido jamás será vencido o Pueblo armado jamás será aplastado, ${ }^{10}$ Por una educación nacional, científica y de masas o A la violencia reaccionaria, violencia revolucionaria. En ese momento, los estudiantes se veían a sí mismos, o así lo manifestaban algunos sectores en sus debates, como la vanguardia de la revolución cultural de nueva democracia mientras que la alianza obrero-campesina lideraría la revolución social, económica y política.

9. Hugo Zemelman, De la historia a la política (México D.F.: Universidad de las Naciones Unidas / Siglo Veintiuno Editores, 1989), 5-195.

10. Enrique Santos Calderón, "De cocteles molotov a senos al aire; recuento de marchas estudiantiles", El Tiempo, 26 de noviembre de 2011. 
En el siglo XXI el uso del simbolismo, del juego y la risa condensados en acciones colectivas que asumen formas carnavalescas se ha vuelto más frecuente junto a otras emergencias como las ocasionadas por la revolución electrónica que plantea nuevas formas de comunicación y de acción en los movimientos sociales. La comunicación se constituye en un espacio estratégico de producción de sentido, de apropiación cultural, así como de reconocimiento de las diferencias. De esta manera, emergen nuevas prácticas de reterritorialización simbólica del mundo de hoy en el que los lenguajes están altamente codificados, hay nuevas formas de narrativa e imaginar lo público y lo privado en las que las diferencias entre lo público y lo privado se diluyen. ${ }^{11} \mathrm{El}$ Internet se vuelve lo público y los medios masivos de comunicación, así como las dinámicas que se generan por las redes sociales y los teléfonos celulares invaden la vida privada de las personas. Estos elementos permiten transcender el ámbito de lo local, entrar en la globalización y en la virtualidad a partir de lo cual se definen nuevas ciudadanías juveniles que hablan de movimientos sociales que se mueven en las redes sociales y plantean nuevos retos relacionados con los asuntos políticos.

Con el uso de las Tecnologías de la Información y Comunicación (TIC) y en particular, de Internet, se dan resistencias múltiples y diversas sobre el ejercicio del poder. Las minorías étnicas, de género, el feminismo, el ambientalismo y los movimientos alternativos son ejemplos de este fenómeno que ha logrado convocar y reunir multitudes alrededor de reivindicaciones económicas, culturales, políticas, religiosas. Estos movimientos en red incluso han llevado a la caída de regímenes como los ocurridos en lo que se denominó la primavera árabe en el norte de África; o a la crisis de gobiernos o instituciones gubernamentales como los indignados en España, el movimiento Occupy Wall Street, el movimiento estudiantil en Chile, entre otros.

Las TIC configuran un nuevo espacio público desde el cual los inconformes resisten, posicionan sus discursos y repelen formas de exclusión y marginalidad. En el siglo XXI, ha cambiado la forma de la protesta estudiantil y en general de los movimientos sociales porque actualmente el ciberespacio facilita otras formas de comunicación. La inmediatez de las redes sociales que comunican en tiempo real, ha jugado un papel decisivo en las movilizaciones mundiales por facilitar cuestiones de identidad (tanto

11. Jesús Martín Barbero, "La globalización en clave cultural: una mirada latinoamericana”, Revista Renglones, n. ${ }^{\circ} 53$ (2003): 18-33. 
propia como colectiva), por el reconocimiento del otro (alteridad) y por permitir compartir un espacio-tiempo en la realización de un objetivo común. El problema ya no es el acceso a los medios de comunicación sino la creación de contenidos originales y de calidad. Esto plantea otras formas de sociabilidad y de subjetividad que han sido discutidas por algunos autores que se presentan a continuación.

\section{La subjetividad política como construcción de sentido y disputa por lo social}

El modelo neoliberal realiza un trabajo sistemático en la producción de subjetividades como parte de la biopolítica que invade la vida de las personas y se manifiesta en el ansia de consumismo, el hedonismo y el pragmatismo. En este contexto la educación se concibe como un eficientismo, en el que la excelencia y la productividad son sus fines que se concretan en una educación para el trabajo y no para la formación integral de sujetos colectivos críticos.

Retamozo $^{12}$ señala que es en el campo de la subjetividad política donde puede darse el proceso de subjetivación que genere otras posibilidades de acción, subjetividad y sujetos políticos alternativos a la subjetividad neoliberal dominante, ya que es en lo social donde opera el trasfondo sedimentado de lo instituyente, que en términos de Castoriadis, ${ }^{13}$ corresponde al imaginario radical, no instituido que se expresa, entre otras múltiples maneras, a través de las consignas en escenarios carnavalescos.

En la triada imaginación, discurso y acción se resuelve la semiosis social, es decir, la construcción social de lo real, tiene lugar discursivamente. ${ }^{14}$ Los discursos se entrelazan a través de una producción histórica de sentido compartido que está en construcción permanente y que varía según el momento histórico, el estudiante que luchó por autonomía y cogobierno en Colombia en 1971 no es el mismo que el del 2011. El discurso se concibe en interacción, un discurso como enunciado que implica prácticas socia-

12. Martín Retamozo, "Orden social, subjetividad y acción colectiva. Notas para el estudio de los movimientos sociales", Athenea Digital, n. ${ }^{\circ} 16$ (2009): 95-123.

13. Castoriadis, "La institución imaginaria de la sociedad".

14. Fernando Bravo, "Semiosis social" (ponencia, Seminario de Convergencias Críticas del Doctorado en Estudios Sociales, Bogotá, 26 de octubre de 2016). 
les, géneros discursivos, prácticas discursivas que nos permiten capturar y producir sentido de manera performativa, es decir, transformando a partir del lenguaje con la producción de imaginarios radicales en la esfera de lo instituyente, de los sentidos y desde una dimensión simbólica tal como lo enuncian Laclau y Mouffe ${ }^{15}$ construimos la sociedad a través de una operación conflictiva, hegemónica, política y discursiva. La instalación de lo instituyente se da como disputa, como lucha, una lucha por la hegemonía, que es lucha por el poder y en las consignas se expresa como una lucha por lo simbólico, por los sentidos, por la hegemonía discursiva.

$\mathrm{Lao}^{16}$ plantea que una disputa que permita instalar lo instituyente requiere la alianza de diferentes formas de opresión e implicaría ir más allá de las identidades particularizantes presentes en los movimientos sociales, lo cual Laclau denomina dislocación. ${ }^{17}$ En palabras de Lao "implosionar las mediaciones múltiples que nos marcan como sujetos y la necesidad no solo de des-marcar (como repetidamente señaló Adolfo Albán), sino también promover la autocreación intersubjetiva para re-existir y re-construirnos a partir de nuevos criterios de afinidad y nuevas formas de comunidad".

Según Laclau, la ampliación de la dislocación, es decir, del componente negativo o conflictivo que existe en toda identidad, por naturaleza incompleta y con presencia de disensos, genera espacios de libertad, instancias de acción y construcción de antagonismo, esto es lo político y su disputa por el orden social. En este planteamiento, dicha dislocación se expresa en el plano del lenguaje (las consignas), y hace parte de lo social que excede a la sociedad, está rodeado de exceso de sentido que el orden establecido no siempre puede controlar y por esa misma razón abre el espacio para la esfera de lo político, de lo instituyente constituido en los sentidos y en la dimensión simbólica del terreno de lo social.

Es así como cuando los estudiantes colombianos acuerdan una consigna que es puesta en el espacio público como por ejemplo, ¡A Abajo la privatización de la educación pública!, ellos plantean una lucha por la enunciación que es una lucha por la hegemonía. Sin embargo, según los autores

15. Ernesto Laclau y Chantal Mouffe, Hegemonía y Estrategia Socialista. Hacia una radicalización de la democracia (Madrid: Siglo XXI, 1987), 8-70.

16. Agustín Lao-Montes, "Las actuales insurgencias políticas-epistémicas en las Américas: giros a la izquierda, giros anti imperiales, giros de-coloniales", Comentario Internacional, n. $^{\circ} 7$ (2007): 173-85.

17. Laclau y Mouffe, "Hegemonía y Estrategia Socialista. Hacia una radicalización de la democracia". 
citados para ser realmente hegemónica tendría que vincular otros sectores que en este caso, también se sientan afectados por la privatización e incluso realizar articulaciones que permitieran enunciar ;Abajo la privatización de los servicios públicos!, lo cual le permitiría salir del marco de las identidades y articularse con otros grupos sociales.

En este sentido, las consignas generan significantes aglutinantes que podrían estar dando cuenta de transformaciones en los procesos de representación hegemónicos. Por ejemplo, las consignas del 2011 Es mejor perder un semestre en la Universidad que la Universidad en un semestre expresaban resistencia a las amenazas de la Ministra de Educación María Fernanda Campo de cancelar el semestre y sancionar a los rectores. Al igual que la Universidad no se vende, se defiende, no somos la generación que va a ver morir la universidad pública o por una universidad del tamaño de nuestros sueños estas consignas, no hablan de cambios estructurales de la sociedad que eran característicos del movimiento estudiantil anterior a la caída del Muro de Berlín y no resuelven los problemas que sugieren, pero sensibilizan frente a la importancia de la universidad pública como bien común y derecho fundamental.

Los estudiantes del 2011 luchaban por el derecho a hablar, a decir lo que se piensa, a investigar, a pensar. Discutían que la función social de la Universidad radica en la constitución de una investigación libre, del ejercicio libre de la razón y de la ciencia, la Universidad como garante del derecho a la democracia, a la libertad de expresarse y a la autonomía. Luchaban por la gratuidad y por la educación como derecho universal, rechazaban la aplicación de los principios de la libertad de mercado en la universidad pública. Todo esto abre un espacio democrático y de posibilidades políticas. Es así como la Mesa Amplia Nacional Estudiantil (MANE) lo planteó en el programa mínimo de los estudiantes universitarios:

La universidad colombiana debe estar ligada a las necesidades más sentidas del pueblo colombiano y al desarrollo y progreso de su mercado interno, por tanto su actividad académica e investigativa estará a su servicio. Esto implica que la universidad pública debe discutir y adoptar un nuevo modelo pedagógico que afronte, discuta y genere alternativas con respecto a las problemáticas sociales, económicas y medioambientales que afronta el país, vincule a los grupos étnicos y culturales que componen la nación colombiana. Entendemos que la extensión universitaria hace parte integral del quehacer académico de la universidad mo- 
tivo por el cual este debe responder a las prioridades y necesidades del pueblo colombiano. ${ }^{18}$

En este mismo sentido, tanto en el Documento Exposición de motivos de una nueva Ley de Educación Superior para un país con soberanía, democracia y pa $z^{19}$ de septiembre del 2012 como en el Articulado Programático de enero de $2013,{ }^{20}$ los estudiantes a través de la MANE, abogan por una universidad popular que sea la consciencia crítica de la sociedad en la que la investigación sea libre y no haya una estandarización de contenidos desarrollada "a través de diferentes herramientas como los procesos de acreditación, las pruebas Saber Pro o la implementación de competencias académicas, ciudadanas o laborales".

Con estas declaraciones, la MANE se pronunciaba con respecto a la inversión de principios que el Sistema Nacional de Acreditación implica ${ }^{21}$ por su violación de la autonomía universitaria impuesta normativamente y que ha generado un gran malestar en la comunidad educativa al lanzarla a responder a criterios estadísticos con formatos y recolección de datos que distan de los principios de la Universidad como son la producción de conocimiento y la investigación libre.

Para la MANE, defender la universidad en el paro nacional estudiantil del 2011, pasaba por revertir la reforma a la Ley 30 y poner en una balanza los intereses individuales que se podrían ver afectados con la cancelación del semestre y los intereses colectivos vulnerados al institucionalizar el ánimo de lucro y la privatización de la educación pública. Ante la amenaza de que se cancelara el semestre, los universitarios planteaban que irían "hasta las últimas consecuencias", no temían a una debacle académica y para hacerlo desplegarían estrategias novedosas de acción política, en las que las formas y no solamente los contenidos de lo que se dice toma importancia. Así lo manifestó a un medio de comunicación un líder estudiantil:

18. Punto VI, Relación Universidad-Sociedad.

19. Mesa Amplia Nacional Estudiantil, "Exposición de motivos de una nueva Ley de Educación Superior para un país con soberanía, democracia y paz", MANE, septiembre de 2012.

20. Mesa Amplia Nacional Estudiantil, "Articulado de Ley de Educación Superior para un país con soberanía, democracia y paz", MANE, 20 de enero de 2013.

21. El Sistema Nacional de Acreditación fue creado por la Ley 30 en 1992 y reglamentado mediante el decreto 2994 en diciembre de 1994 con el que se crea el Consejo Nacional de Acreditación. Este sistema impone unos nuevos criterios tecnocráticos que escalan el discurso de la empresa privada en la educación y agudizan el malestar y el hartazgo en la comunidad educativa. 
Preferimos perder un semestre en la universidad que la universidad en un semestre ...rechazamos cualquier agresión que se le pretenda hacer a cualquier miembro de la comunidad universitaria, somos ante todo proyecto de país, y en ese sentido vamos a rechazar cualquier agresión contra un profesor, un rector o un estudiante... hemos venido insistiendo en manifestaciones creativas como fue la 'besatón' y en esa lógica seguirá operando la comunidad universitaria. ${ }^{22}$

En sus manifestaciones, en sus formas de decir y de actuar tal como aparecen en la consigna y en las afirmaciones citadas en el párrafo anterior, se expresan conexiones con otros sectores más allá de los estudiantes, se expresa pluralismo, creatividad en los repertorios de lucha y claramente la decisión de construir un nosotros, una comunidad.

Otro significante aglutinante que expresa una demanda histórica del movimiento estudiantil tiene que ver con el rechazo a la desfinanciación de la universidad pública. Es así como en el 2018 se escuchaban los ecos del acontecimiento inaugurado por la MANE en el 2011 referidos a la lucha contra la desfinanciación de la universidad pública. Esta reivindicación entraña una relación social estructurada como es la privatización de la educación y condensa múltiples sentidos. Alrededor de la defensa de la universidad pública y la educación como derecho y no como servicio se expresaron y produjeron nuevas subjetividades, es posible que los sujetos estén mirando su realidad desde otras perspectivas. Vale la pena indagar si podríamos estar hablando de nuevos espacios de enunciación que se puedan convertir en significantes aglutinantes que den lugar a proyectos políticos que rompan con procesos de representación hegemónica.

Virviescas y Puentes ${ }^{23}$ señalan tres momentos importantes que han contribuido a una subjetividad en la que se naturaliza ser acreedor-deudor y que es precisamente la que orienta el programa de Ser Pilo Paga (SPP). Sin embargo, es posible que con las acciones colectivas del movimiento estudiantil del 2011 y las que se siguen dando en esa misma línea por la defensa de la universidad pública, gratuita y de calidad, se instalen otras subjetividades, otros sentidos que disputan lo social y que tienen que ver

22. Omar Gómez, "Pese a posibilidad de perder el semestre, universitarios no levantan el paro", El Espectador, 25 de octubre de 2011.

23. Lina María Virviescas y Catalina Puentes, "La relación acreedor-deudor en el sistema de educación superior en Colombia: un análisis de la pedagogía de la deuda -programa 'Ser Pilo Paga"' (tesis maestría, Universidad Javeriana, 2016), 90-143. 
con la educación como derecho, la universidad como consciencia crítica de la sociedad y todo esto a partir de lenguajes que producen subjetividad política y sujetos políticos.

Como un ejemplo de lo anterior, el 9 de octubre de 2017 en Bogotá, los estudiantes realizaron una movilización masiva en rechazo al programa Ser Pilo Paga (SPP) y con ella agendaron la discusión en los medios planteando su preocupación frente a que este proyecto de SPP se convierta en política pública. La consigna ser pilo no paga si la pública se acaba, así como consignas del 2011 como cinco años estudiando y quince pagando o la educación es un derecho, tienen una gran carga expresiva y proponen para el debate público una problematización social como es la desfinanciación de la Universidad Pública.

En el 2018, el gobierno de Iván Duque con la Ministra María Victoria Ángulo a la cabeza, anunciaron la reestructuración del programa SPP con un proyecto alterno titulado Generación E (E por Excelencia), junto a una Ley de Financiamiento contingente al ingreso, pero que básicamente sigue incentivando una política de financiación a la demanda, es decir, a créditos, al ICETEX y no a la oferta que no resuelve la crisis presupuestal de las universidades colombianas. Esta problemática no es nueva, viene desde los años setenta, se agudiza con el auge neoliberal en los noventa y con la Ley 30 producto de lo cual a la fecha las universidades públicas tienen un déficit de 16 billones de pesos que se conoce como la deuda histórica del Estado con las universidades públicas.

La desfinanciación de la universidad pública parece que fuera una iniciativa deliberada que va en consonancia con el modelo económico privatizador, excluyente que históricamente ha descuidado lo social. Sin los recursos suficientes, las universidades no pueden cumplir sus funciones misionales como son la docencia, la investigación y la extensión y se ven obligadas a realizar proyectos para producir recursos, dinero, lejos de la academia y de la sociedad y que nada tiene que ver con proyectos prioritarios al servicio de una educación científica y democrática.

El Estado neoliberal prefiere destinar los recursos que serían para la educación pública a vías de cuarta generación o al presupuesto para la guerra o para pagar los intereses de la deuda externa. El programa SPP claramente financia la demanda con créditos que mantienen endeudados a los jóvenes y a sus familias, es decir el dinero invertido no va a la base presupuestal de las universidades con lo cual se financiaría la oferta. Con lo que 
SPP financiaba 40000 estudiantes se podrían haber formado 650000 en universidades públicas.

Los estudiantes rechazan la Ley de Financiamiento contingente al ingreso y en su momento rechazaron el programa de SPP con el argumento de que son programas populistas y demagógicos. El Estado con SPP y con su reencauche en la política de la Generación E, asigna becas a los estudiantes más pilos, con los resultados de las pruebas Saber Pro ${ }^{24}$ más altos del país, de estratos 1 y 2 que nunca podrían acceder a la universidad si no fuera por tales programas. También habla de equidad cuando dice preocuparse por los más pobres pero en realidad no les da una beca como lo afirma, sino que les hace un crédito condonable. ${ }^{25}$

En la expresión de subjetividad política, con formas de razonamiento como la hipergeneralización los estudiantes producen sentido como La educación es un derecho no un privilegio. También hacen uso de otras figuras literarias como la analogía y la equivalencia, la sinécdoque y la metonimia al establecer relaciones entre universidad-empresa-mercancía-lucro y proponer a cambio universidad-gratuidad-calidad-universalidad-derecho.

La mayoría de los estudiantes pilos que han participado hasta la fecha en el programa, prefieren ir a las universidades privadas porque el ofrecimiento plantea una competencia desigual entre las universidades públicas y las privadas. Estas últimas gozan de mayor presupuesto, buena infraestructura, mejor remuneración a los docentes y una mejor imagen social. Es de anotar que los estudiantes de las universidades también se han movilizado en contra de este Programa, muchos de ellos son estudiantes que para poder estudiar en las privadas han tenido que endeudarse con bancos o con el ICETEX. SPP y Generación E están diseñados para que quienes no terminen la carrera paguen el valor recibido, lo cual con los índices de deserción

24. Las pruebas Saber Pro corresponden a un examen que es requisito para grado de todos los estudiantes que adelanten programas de pregrado en instituciones de educación superior en Colombia.

25. Los argumentos que se destacan aquí sobre SPP fueron presentados en los medios (Emisora la W, Semana en Vivo, El Tiempo y El Espectador) en los días posteriores a la movilización del 9 de octubre de 2017. Con la llegada del gobierno de Iván Duque se han anunciado reformas al programa, que básicamente incentiva la selección de universidades públicas por parte de los "Pilos" al exigir en caso de seleccionar universidades privadas, el $25 \%$ del valor de la matrícula a la Universidad elegida y el $25 \%$ al estudiante favorecido. Al parecer, la idea de financiar la demanda, a través de transferencia de recursos al ICETEX, y no la oferta, se mantiene y sigue generando tensiones con el movimiento estudiantil que ha posicionado la idea de que es necesario que el Estado financie la oferta. 
del $40 \%$ de estudiantes en las universidades privadas representa un peligro y podría endeudar a los beneficiarios.

Los estudiantes en sus comunicados han planteado que SPP es un sistema de transferencia de recursos del Estado a las universidades privadas. Dicho programa recorta los recursos para Ciencia y Tecnología en la educación pública, fortalece el ICETEX que endeuda y arruina a los estudiantes y a sus familias. El fortalecimiento del ICETEX como política de desfinanciación de la educación pública tampoco es nuevo pero se sigue dando en 2019 cuando suena en la radio la noticia de que los estudiantes universitarios se lanzan a las calles con la consigna El ICETEX te arruina para reclamar al ICETEX la refinanciación de sus deudas, actualizando el conflicto del endeudamiento de las familias que no es solamente un problema en Colombia sino en otros países de América Latina, como Chile en donde los estudiantes y sus familias se han unido de manera espontánea para luchar contra las políticas neoliberales de privatización en la educación.

En la movilización del 9 de octubre de 2017 contra SPP surgieron interrogantes planteados por algunos profesores que participaban en la marcha. ¿Por qué al llegar al Ministerio de Educación Nacional, los estudiantes no se dirigieron a los asistentes con un megáfono o con una voz potente para dar un parte de victoria y evidenciar que salían fortalecidos? Al contrario, los estudiantes, sin líderes, sin representantes, sin voceros, se sentaron tranquila y plácidamente en las zonas verdes alrededor del ministerio, descansaron un rato y se marcharon sin mayor algarabía. El triunfo de la acción colectiva ya estaba dado, pero se manifestaba desde nuevas posibilidades de vida que plantean nuevas formas de estar juntos y de hacer política, el posicionamiento de otros sentidos, de otras maneras, el grito de ser pilo no paga si la pública se acaba retumbaba en las paredes del ministerio, rearticulaba y producía formas discursivas distintas.

Lazzaratto ${ }^{26}$ para discutir lo que sería la apertura de campos de posibilidades a través de la política trae a Foucault, quien hacia el final de su vida anhelaba que los movimientos políticos no solamente se resistieran y se defendieran, sino que se afirmaran planteaba:

26. Mauricio Lazzaratto, Políticas del acontecimiento, trad. Pablo Esteban Rodríguez (Buenos Aires: Tinta Limón, 2006), 43-80. 
[...] en tanto que fuerzas creativas. Esto podría constituir un cambio radical en relación con la tradición del movimiento obrero, ya que el acontecimiento político define una asimetría en la dialéctica con la cual se ha aprehendido, siguiendo al marxismo, el conflicto y la lucha. El "no" dirigido al poder no es más el punto de partida de una lucha dialéctica contra él, sino la apertura de un devenir. Decir "no" constituye la forma mínima de resistencia. Esta última debe abrir un proceso de creación, de transformación de la situación, de participación activa en el proceso. Esto es resistir, según Foucault.

En la cita anterior se sugiere que la resistencia recoge una multiplicidad de enunciaciones, de cuerpos, de enunciados de espiritualidad, es pasado, presente y futuro y más que en los enunciados figura en los cuerpos, modifica las formas de existencia, las maneras de sentir, de afectar y de ser afectado. Es decir, las formas de hacer política tradicionales han cambiado y ya los mecanismos de liderazgo y representación no son suficientes sino que los movimientos sociales actúan desde la multiplicidad, la alegría, el carnaval, el afecto y la creatividad.

Esto también podría estar aflorando en el movimiento estudiantil en Colombia y se podría estar expresando no solamente en las organizaciones estudiantiles sino en los enunciados de los líderes y activistas, las de los padres de familia, las de los profesores, las de las universidades públicas, las privadas, los colegios de secundaria, las de los tropeleros que llegaron a acuerdos para no seguir luchando desde la capucha, las de los estudiantes no organizados, antes silenciosos y hasta ahora invisibilizados.

\section{Formas carnavalescas con las que se agitan las consignas}

Con el fin de insistir en el carácter significativo, simbólico y representacional que tienen las consignas y lo carnavalesco, acudo a la sociología cultural y su propuesta de estudiar el significado, destacando lo simbólico como referente para la cohesión social en donde la intersubjetividad, el lenguaje, el discurso y la acción aportan la idea de que el sujeto usa los sistemas conceptuales de su cultura y los sistemas lingüísticos y demás sistemas representacionales para construir sentido, para hacer del mundo algo significativo, y para comunicarse con otros sobre ese mundo. La representación es la forma como un determinado sujeto significa el mundo real o significa una realidad imaginaria. El sentido es construido mediante la significación 
es decir, por las prácticas que producen sentido y tiene un carácter performativo que propaga unos significados que más allá de si son reales o artificiales, se incorporan a las maneras de ver y de sentir de las comunidades. ${ }^{27}$

A través de otras formas de lo político en las que el movimiento estudiantil colombiano ha retomado elementos inaugurados por los estudiantes franceses en mayo de 1968 con consignas como La imaginación al poder, prohibido prohibir o isomos todos judíos alemanes! También los expresados en el 2011 por el movimiento estudiantil chileno, por los Indignados, por Occupy Wall Street con consignas como ;Somos el 99 \%!, los banqueros nos robaron el futuro, otro mundo es posible, o incluso retomando los cánticos de los hinchas futboleros, los estudiantes combaten con formas carnavalescas, la matriz mediática y el imaginario social que existe acerca de la universidad pública como por ejemplo se sabe cuándo se entra, pero no cuando se sale, el cual evidencia una estigmatización de la universidad y de quienes estudian en ella como revolucionaria, tirapiedras, llena de guerrilleros y por lo tanto se sugiere que sería una institución inestable y de baja calidad.

Bajtín ${ }^{28}$ señala que el carnaval es parte de la vida cotidiana de las comunidades populares, tiene un carácter utópico, festivo, sin jerarquías y es posible comprenderlo a partir de una concepción dialógica del lenguaje que va más allá de la lengua, se ubica en la enunciación que involucra elementos subjetivos, cognitivos, valorativos, estéticos, afectivos, éticos y políticos no inherentes a la lengua pero sí a la enunciación como acto de lenguaje que transgreden el orden simbólico hegemónico. Según este autor, el carnaval no pertenece exactamente al campo de lo artístico sino que se ubica en un lugar intermedio entre el arte y la vida, es la vida misma con elementos de juego en donde la cultura popular y el humor tienen un lugar preponderante.

Lo carnavalesco en el movimiento estudiantil se refiere a las acciones colectivas estudiantiles de carácter estético-político con las que los estudiantes irrumpen en el espacio público, su lugar de enunciación, con un lenguaje visual, colectivo y transgresor. Una de las características de estas

27. Alexander Jeffrey, Sociología Cultural. Formas de clasificación en las sociedades complejas (México D.F.: Anthropos / CLACSO, 2000), 12.

28. Mijail Bajtín, La cultura popular en la Edad Media y el Renacimiento (Madrid: Alianza. Editorial, 2003), $4-11$. 
irrupciones es el uso de la sátira, el sarcasmo, el ridículo, la analogía y la ironía para denunciar y parodiar a los representantes del poder.

En el carnaval, las jerarquías desaparecen y las relaciones simbólicas de poder se transgreden y se reordenan. Bajtín ${ }^{29}$ caracteriza lo carnavalesco como un mundo al revés de convivencia comunitaria y festividad. La máscara desborda la identidad y pone en diálogo el sistema de valores dando paso a un humor radical que pone en ridículo los significantes establecidos en el que el lenguaje simbólico es relativo y transitorio y amplía las posibilidades del sentido planteando de este modo una confrontación semiótico-lingüística que exige crítica, intelecto e interpretación pues lo que se humoriza o satiriza, no es evidente.

La confrontación semiótico-lingüística a la que remiten las consignas del movimiento estudiantil y su puesta en escena con elementos carnavalescos expresan y producen subjetividad, sentidos compartidos, es decir, como lo señala Retamozo ${ }^{30}$ la subjetividad o las "rearticulaciones moleculares de la subjetividad colectiva" que son polisémicas, contradictorias, en ocasiones conservadoras, caducas e incluso neoliberales, pueden conducir a la politización de las relaciones sociales a una disputa por la legitimidad, a nuevos espacios de enunciación, a una rearticulación del campo de la experiencia como acción y lucha por el orden social y rearticulación de los significados hegemónicos.

Torres ${ }^{31}$ concibe estas manifestaciones como estrategias de resistencia en las que los sectores dominados de la sociedad despliegan unas "prácticas culturales del terreno de la oralidad y la imaginería popular, prácticas como la ironía, la picardía, el chiste, los apodos, los juegos de palabras y las inversiones simbólicas que transgreden el poder". Según Scott ${ }^{32}$ a estas prácticas se les denomina infrapolíticas, es decir, se dan como un discurso oculto que se manifiesta más allá del terreno de lo visible. Así como se hace cuando se usa una máscara, o se manifiesta la ironía o el sarcasmo, los subordinados defienden a escondidas "un espacio social en el cual se podrá expresar una disidencia marginal al discurso oficial de las relaciones de poder". En este

29. Ibíd, 103.

30. Retamozo, "Orden social, subjetividad y acción colectiva", 107.

31. Alfonso Torres, "Las lógicas de la acción colectiva. Aportes para ampliar la comprensión de la acción colectiva", Cuadernos de Sociología 36, (2002): 33-62.

32. James Scott, Los dominados y el arte de la resistencia, trad. Jorge Mora Aguilar (México D.F.: Era, 2004), 217. 
sentido, las formas lúdicas y carnavalescas del movimiento estudiantil podrían ser comprendidas como una infrapolítica que resiste al poder desde el humor y la parodia.

En el 2011 veíamos cómo los estudiantes, profesores y trabajadores se tomaban de las manos para entre todos dar un gran abrazo que cubriera toda la Universidad Pedagógica Nacional o que en las marchas usaban máscaras, hacían performances, retomaban juegos infantiles para parodiar los ataques del gobierno en contra de la universidad pública y en contra de persecuciones a los líderes populares.

Dentro de las parodias estaba la de los medios en la que por ejemplo una marioneta dirigía la cámara hacia la masiva manifestación y un periodista luego decía vinieron cuatro gatos para caricaturizar las mentiras de los medios haciendo uso del humor radical, la denuncia y la sátira. Una de las rondas infantiles de las manifestaciones era la de Juguemos en el bosque mientras el lobo no está ¿Dónde está? Y el lobo contestaba: Estoy matando líderes populares o Estoy privatizando la educación pública y todos gritaban y corrían a esconderse del lobo. Estos ejemplos hablan de un ambiente lúdico y carnavalesco que plantea la risa como irreverencia que produce y expresa significados subalternados, marginados, naturalizados o invisibilizados, que configuran una subjetividad política.

La fiesta y las manifestaciones carnavalescas en que se han convertido las manifestaciones estudiantiles en tiempos de movilización son espacios para la agitación de consignas que han logrado dejar sin piso la estigmatización promovida entre otros actores por los medios de comunicación y en el 2011 recibieron el apoyo de amplios sectores de la sociedad. Han logrado contagiar y crear deseos, las convocatorias a través de pancartas donde se exponen las consignas y las demandas han devenido en expresiones artísticas y culturales en las que los jóvenes universitarios irrumpen con "performances, montajes, títeres, obras de teatro, guitarreos, etc., las cuales se suceden una tras otra a través de la marcha, en una suerte de competencia por quién alcanza la mayor creatividad". ${ }^{3}$

La marcha de los estudiantes colombianos en el siglo XXI se convierte en acción instituyente; la plaza de Bolívar se constituye en un lugar de

33. Juan Urra, "La movilización estudiantil chilena en 2011: Una cronología", Observatorio Social de América Latina, . $^{\circ} 31$ (2012): 23-37. 
emergencia de los sujetos sociales en las que sus "prácticas espaciales, sus representaciones del espacio y los espacios de representación ayudan tanto a situar la disputa por los lugares de emergencia de los sujetos sociales como las operaciones de producción-apropiación del espacio-tiempo". ${ }^{34} \mathrm{Al}$ ver a los jóvenes en comunidad coreando sus consignas, alegres, solidarios, plácidos sin querer abandonar el lugar, se podría pensar que es liberador al igual que observarlos en campamento en el que la solidaridad, el pluralismo y la ética del cuidado predominan, a pesar de expresiones estudiantiles que se enmarcan más en un hedonismo individualista caracterizado por el consumo de drogas, entre otros comportamientos que son tolerados y aceptados por la comunidad estudiantil como un rasgo de diferencia.

Los estudiantes toman la palabra a través de expresiones artísticas con las que hacen visibles y decibles las problemáticas de la universidad, su baja calidad. Ponen en entredicho las visiones que no tienen en cuenta otros indicadores de calidad como aquellos que señalan que las pruebas saber pro no son el único criterio para hablar de calidad de la educación. Si se toman como indicadores de calidad los exámenes oficiales y otros indicadores, las pruebas de valor agregado indican que tres universidades públicas tienen los más altos estándares de calidad al lograr una mayor diferencia en cuanto al nivel con el que llegan los estudiantes y el nivel de avance que se manifiesta al compararlo con el que salen, principalmente en competencia lectora. Los estudiantes agendan la discusión sobre la desfinanciación de la educación pública, instauran nuevas posibilidades de vida que expresan potencialidades y hacen política.

Como plantea Vermeren 35 "La política existe cuando la reivindicación de la igualdad perturba el juego que distribuye los lugares dentro de la sociedad; cuando personas sin palabra, sin existencia, reivindican la igualdad en un campo de desigualdad, en un campo donde estas personas no existen como sujetos políticos". Una de las maneras como los jóvenes universitarios expresan su creatividad es a través de sus cuerpos, lo cual se evidencia en la consigna iiResistencia!!, cuya fuerza expresiva radica en que en medio de las movilizaciones, la marcha se frena más o menos por cien metros, los estudiantes se sientan o se acuclillan por unos segundos, luego se corea con

34. Retamozo, "Orden social, subjetividad y acción colectiva. Notas para el estudio de los movimientos sociales".

35. Patrice Vermeren, "Las Universidades contra la Universidad", Paralaje, n. 7 (2011). 
energía la consigna ${ }_{i}$ Resistencia!! y los jóvenes corren fuerte, rápido, armónica y alegremente instalando un poder que se gana todas las miradas, un poder que es transgresor, creador y fortalece vínculos identitarios.

Para concluir este apartado, las consignas que se comentaron atrás, es necesario mirarlas en el entendido de que las luchas en el movimiento estudiantil, aunque se dan de manera discontinua, plantean unas demandas que se mantienen en el tiempo y se reactivan periódicamente como son la lucha por el presupuesto, por la calidad, por la democracia y la autonomía entre otras, esta es su memoria larga y es la que reaviva la lucha no solamente cuando hay una estructura de oportunidades políticas como lo plantea Cruz, ${ }^{36}$ sino cuando el bien común se ve afectado por medidas gubernamentales. Es así como el tema de la desfinanciación de la educación pública se articula con todas las demandas por presupuesto que desde los años 70 vienen dando los estudiantes colombianos, se visibilizaron en el 2011 y ahora se actualizan en el 2018 en la misma dinámica de la memoria larga del movimiento estudiantil que plantea discontinuidades, latencias y permanencias.

\section{Conclusión}

La acción social se construye a partir de nuestros propios relatos, a partir del otro. De esta manera, la realidad social se comprende desde nuestra propia historicidad, desde nuestro presente que nos permite dar cuenta de lo inacabado, de lo potencial, de lo no instituido, de lo no consensuado. En este contexto, se concibe la realidad como un espacio de posibilidades en la que el sujeto interviene para construir futuro, construir sentidos a través del lenguaje y del diálogo, que son los que nos permiten desplegar todas nuestras facultades y poner en juego nuestros deseos y nuestras emociones.

Esta perspectiva reivindica el papel activo del sujeto que imagina y al imaginar estructura su realidad, esta es la perspectiva de lo micro y lo macro. En ella, la acción significativa puede ser considerada como texto, en el que se exploran códigos (normativizados) y narrativas (producción de sentido) e interpretaciones y reconocimientos, en diversos discursos con el

36. Edwin Cruz, "La reforma de la educación superior y las protestas estudiantiles en Colombia", Postdata $18,{ }^{\circ} 1(2013): 51-71$. 
fin de entender qué hace a algunos hechos sociales plenamente significativos lo cual implica la apertura de otros mundos posibles en donde la ficción está dada precisamente por la posibilidad de crear mundos. Así imaginar se convierte en praxis, en acción, en enunciación, en imaginario radical que produce sentido colectivamente, en interacción con el otro y de esa manera es acción social, significativa y genera cohesión social. ${ }^{37}$

En las narraciones o relatos que emergen de la cultura, nuestra experiencia se junta, la experiencia del tiempo histórico y social confluye y en un ejercicio de memoria, relatamos e imaginamos el pasado, el presente y el futuro. Ese ejercicio de imaginación se da en el plano de lo subjetivo y aunque se encuentra influido por factores contextuales de orden socio-histórico no está determinado por ellos, sino más bien, por el modo en el que las personas hacen significativas sus vidas y sus sociedades, los modos en que los actores sociales impregnan de sentimiento y significación su mundo y esto se observa en las acciones colectivas del movimiento estudiantil.

En su disputa por lo social, el movimiento estudiantil con las consignas del 2011 y sus ecos en el 2018 reabre, agenda y visibiliza la discusión sobre asuntos públicos como la educación como derecho, el papel de la universidad en la sociedad, la importancia de lo público y de la universidad pública en particular, los peligros del endeudamiento, la gratuidad, la universalidad, el financiamiento de la demanda y no de la oferta, entre otros asuntos. Mientras la subjetividad del capitalismo tardío nos habla de autogestión, eficiencia y productividad, el movimiento estudiantil universitario colombiano contesta con sentidos alrededor de lo público, lo científico, de calidad y de cara a la sociedad. La lucha contra la privatización y todo lo que implica socialmente esa política se ha convertido en una demanda que moviliza múltiples sentidos por ampliar la brecha entre ricos y pobres y aumentar la exclusión e inequidad de los sectores sociales que bajo su égida no podrían acceder a la educación.

En su lucha por el sentido que se da en el plano discursivo, simbólico e imaginario, el movimiento estudiantil posiciona códigos alternativos en el orden de lo ético, político, valorativo y cognitivo. Al movilizar sentidos construye sus demandas, sus adversarios y sus espacios de participación. Esta disputa entraña la lucha entre lo nuevo y lo viejo, es contradictoria y

37. Alexander, "Pragmática cultural. Un nuevo modelo de performance social". 
confronta diferentes tipos de sujetos que se enfrentan de manera diferente a las problematizaciones que visibilizan las consignas en el territorio callejero y carnavalesco.

La alegría carnavalesca de las acciones colectivas del movimiento estudiantil podría estar indicando transformaciones en la subjetividad que es necesario comprender y caracterizar. Vale la pena indagar si podríamos estar hablando de unos nuevos sujetos políticos o si simplemente lo novedoso del movimiento estudiantil radica en el cómo de sus acciones colectivas y sus demandas e identidad no han cambiado, pues básicamente han luchado por democracia universitaria, calidad, cobertura y presupuesto. Desde el plano de lo ontológico también se hace necesario definir ¿quién es el sujeto político al que hace referencia este artículo?, ¿fueron las cinco organizaciones históricas del movimiento estudiantil las que catapultaron el movimiento?, ¿quién es el sujeto político que aparecía desde todos lados cuando la MANE convocaba y que ahora se opone a SPP?, ¿el hablante colectivo performativo y revolucionario era esa multitud de la que hablan Negri y Hardt que sintió que compartía unos deseos comunes que lo llevaban a salir a las calles y ejercer su ciudadanía más allá de las organizaciones políticas?, ¿quiénes salen disfrazados, parodiando, con sus antorchas, con sus rondas infantiles llenas de ironía contra la Ministra, contra Uribe, con máscaras de $\mathrm{V}$ de venganza, con sus cuerpos desnudos?

Estas son preguntas que no puedo responder aún porque es muy probable que el movimiento estudiantil en el siglo XXI sea un entramado cruzado por lo subordinado y lo dominante en el que los grandes debates se superponen y se da un tránsito entre la alternatividad, la marginalidad y la continuidad con lo que ha existido. Sin embargo, la MANE y sus ecos en el presente hizo ver que están emergiendo otras formas de politicidad que seguramente configuran un nuevo sujeto político que siempre está en proceso, es inacabado, no fijo, no estático.

\section{Bibliografía}

Alexander, Jeffrey. Sociología Cultural. Formas de clasificación en las sociedades complejas. México D.F.: Anthropos / CLACSO, 2000. . "Pragmática cultural. Un nuevo modelo de performance social." Revista Colombiana de Sociología, n. 24 (2005): 9-67. doi: 10.15446/rcs

Ayala Cruz, Gustavo Xavier. "Izquierdas latinoamericanas: de la alternancia a la alternativa". Comentario Internacional, n. ${ }^{\circ}$ (2007): 79-92. 
Bajtín, Mijail. La cultura popular en la Edad Media y el Renacimiento. Madrid: Alianza. Editorial, 2003.

Barbero, Jesús Martín. "La globalización en clave cultural: una mirada latinoamericana”. Revista Renglones, n. ${ }^{\circ} 53$ (2003): 18-33.

Bravo, Fernando. "Semiosis social". Ponencia presentada en el Seminario de Convergencias Críticas del Doctorado en Estudios Sociales, Bogotá, 26 de octubre de 2016.

Candau, Joel, Memoria e Identidad. Traducido por Eduardo Rinesi. Argentina: Ediciones del Sol, 2001.

Castoriadis, Cornelius. La institución imaginaria de la sociedad. 1 vol. Buenos Aires: Tusquets, 1999.

Corsiglia Mura, Lucía. Jóvenes piqueteros y encapuchados: algunas preguntas sobre las marcas de lo plebeyo en las formas de la acción colectiva. Argentina: Ediciones de Periodismo y Comunicación Social / Observatorio de Jóvenes, Comunicación y Medios, 2012.

Cruz, Edwin. "La reforma de la educación superior y las protestas estudiantiles en Colombia”. Postdata 18, n. 1 (2013): 51-71.

Gómez, Omar. "Pese a posibilidad de perder el semestre, universitarios no levantan el paro". El Espectador. 25 de octubre de 2011.

Jelin, Elizabeth. Los trabajos de la memoria. Madrid: Siglo XXI, 2002.

Kincheloe, Joe y Mclaren, Peter. "Replanteo de la teoría crítica y de la investigación cualitativa". En Manual de investigación cualitativa. 2 vol., compilado por Norman K. Denzin e Yvonna S. Lincoln. Barcelona: Gedisa, 2012.

Laclau, Ernesto y Chantal Mouffe. Hegemonía y Estrategia Socialista. Hacia una radicalización de la democracia. Madrid: Siglo XXI, 1987.

Lao-Montes, Agustín. "Las actuales insurgencias políticas-epistémicas en las Américas: giros a la izquierda, giros anti imperiales, giros de-coloniales". Comentario Internacional, n. ${ }^{\circ} 7$ (2007): 173-85.

Lazzaratto, Mauricio. Políticas del acontecimiento. Traducido por Pablo Esteban Rodríguez. Buenos Aires: Tinta Limón, 2006.

Mesa Amplia Nacional Estudiantil. "Articulado de Ley de Educación Superior para un país con soberanía, democracia y paz”. MANE, 20 de enero de 2013. 〈https://bit.ly/38SUw1J〉.

"Bases fundamentales para una propuesta de educación superior. Por un país con soberanía, democracia y paz”. MANE, 15 de octubre de 2013. «ttps:// bit.ly/36AE3hs>.

"Exposición de motivos de una nueva Ley de Educación Superior para un país con soberanía, democracia y paz". MANE, septiembre de 2012. 〈https:// bit.ly/2Oa6MDb>.

"Elementos preliminares de articulado para la propuesta de ley alternativa de educación superior" MANE, septiembre 2013. 〈https://bit.ly/37FoMgG〉. 
Melucci, Alberto. Acción colectiva, vida cotidiana y democracia. México: El Colegio de México, 1999.

Páramo, Pablo. La investigación en Ciencias Sociales. Bogotá: Universidad Piloto de Colombia, 2013.

Retamozo, Martín. "Orden social, subjetividad y acción colectiva. Notas para el estudio de los movimientos sociales". Athenea Digital, n. ${ }^{\circ} 16$ (2009): 95-123. doi: $10.5565 / \mathrm{rev} / \mathrm{athenead} / \mathrm{v0n} 16.560$.

Russi, Bernardo. "Grupos de discusión: De la investigación social a la investigación reflexiva”. En Técnicas de investigación en sociedad, cultura y comunicación, coordinado por Luis Jesús Galindo Cáceres. México D.F.: Addison Wesley Longman, 1998.

Santos Calderón, Enrique. "De cocteles molotov a senos al aire; recuento de marchas estudiantiles". El Tiempo, 26 de noviembre 2011.

Sierra, Francisco. "Función y sentido de la entrevista cualitativa en investigación social”. En Técnicas de investigación en sociedad, cultura y comunicación, coordinado por Luis Jesús Galindo Cáceres. México D.F.: Addison Wesley Longman, 1998.

Scott, James, Los dominados y el arte de la resistencia. Traducido por Jorge Aguilar Mora. México D.F.: Era, 2004.

Torres Alfonso. "Las lógicas de la acción colectiva. Aportes para ampliar la comprensión de la acción colectiva". Cuadernos de Sociología 36, (2002): 33-62.

Urra, Juan. "La movilización estudiantil chilena en 2011: Una cronología". Observatorio Social de América Latina, n. ${ }^{\circ} 31$ (2012): 23-37.

Vermeren, Patrice. "Las Universidades contra la Universidad". Paralaje, n. ${ }^{\circ} 7$ (2011).

Virviescas, Lina María y Catalina Puentes. "La relación acreedor-deudor en el sistema de educación superior en Colombia: un análisis de la pedagogía de la deuda-programa 'Ser Pilo Paga'”. Tesis de maestría, Universidad Javeriana, 2016. 〈https://bit.ly/2SfPJ51〉.

Yudice, George. El recurso de la cultura: usos de la cultura en la era global. Barcelona: Gedisa, 2002.

Zemelman, Hugo. De la historia a la política. México D.F.: Universidad de las Naciones Unidas / Siglo Veintiuno Editores, 1989. 